de novo. Previous investigations in our Laboratory have shown ${ }^{6}$ that the inhibition of carbon-14 labelled formate incorporation in vivo into the acid-soluble adenine of leukæmia-infiltrated mouse spleen can be related quantitatively to the dose of amethopterin administered to the animals. Fig. 2 shows the dose-response curves obtained with amethopterin and tetrahydroamethopterin in this system. It can be seen that, at low doses, both drugs produced similar partial inhibition. However, beyond a level of about $0.32 \mathrm{mgm}$./kgm. of tetrahydroamethopterin, no increased inhibition was observed. This is in contrast to the marked inhibition produced by higher doses of amethopterin.

The present work has shown that tetrahydroametho. pterin is more toxic to normal mice than is amethopterin at equivalent dose-levels. In mice bearing advanced leukæmia L1210, tetrahydroamethopterin also appeared to cause somewhat more extensive regression of the local tumour than amethopterin. However, the increased toxicity of tetrahydroamethopterin was proportionately greater than the antitumour effect, so that there was a net loss of antileukæmic effectiveness. Thus, the toxicity of tetrahydroamethopterin relative to amethopterin for host and tumour cells is, in fact, similar to that reported in the bacterial studies ${ }^{1}$. The biochemical basis for this greater toxicity of tetrahydroamethopterin is not known. One possibility is that it is a more effective antagonist of the reduced, coenzymically active forms of folic acid than amethopterin.

We are doing work on the biological and biochemical activity of the reduced folic acid antagonists.

J. A. R. MEAD

J. M. VENDITTI

A. W. SCHRECKER

A. Goldin

Laboratory of Chemical Pharmacology, National Cancer Institute.

R. L. KISIIUK

Laboratory of Nutrition and Endocrinology,

National Institute of Arthritis and Metabolic Diseases,

National Institutes of Health, Bethesde, Maryland.

' Kisliuk, R. L., Nature, 188, 584 (1960).

${ }^{2}$ Goldin, A., Venditti, J. M., Humphreys, S. R., and Mantel, N., J. Nat. Cancer Inst., 21, 495 (1958).

${ }^{3}$ Kisliuk, R. L., J. Biol. Chem., 227, 805 (1957).

- Humphreys, S. R., and Goldin, A., J. Nat. Cancer Inst., 23, 633 (1959).

${ }^{5}$ Goldin, A., Greenspan, E. M., Venditti, J. M., and Schoenbach, E. B., $J$. Nat. Cancer Inst., 12, 987 (1952).

- Schrecker, A. W., Mead, J. A. R., Lynch, M. R., and Goldin, A., Cancer Res., 20, 876 (1960).

\section{Ovine Fotal Resorption caused by Toxoplasma gondii Infection}

WASTAGE in ovine reproduction due to infection of the pregnant ewe by Toxoplasma has been described in New Zealand ${ }^{1,2}$, Australia ${ }^{3,4}$ and the United Kingdoms. Experimental infection has on several occasions ${ }^{1,6}$ confirmed its role as a cause of perinatal mortality. Following experimental infection, ovine toxoplasmosis has now been observed to cause resorption of the fotus in addition to perinatal mortality.

Experimental infection of ewes, which were 101-122 days pregnant, was effected by intraperitoneal inoculation with undiluted peritoneal exudate from infected mice. Nine ewes were thus infected and kept under surveillance in a small enclosed pen until parturition. Following inoculation, three ewes showed evidence of a sanguineous discharge at the vulva and were therefore killed.

In one ewe, autopsied sixteen days after inoculation, twin foetuses, which were partially resorbed, were still distinguishable and the placentomes remained intact, although the intercotyledonary component of the fœetal membranes had disappeared. The placentomes showed lesions of focal necrosis similar to those typically seen in cotyledons from infected fœetal membranes ${ }^{2}$.

The two other ewes were not autopsied until 30 and 40 days after inoculation, at which stage no fotus or fœetal membranes remained obvious; however, there was considerable enlargement of the caruncles, these being concave and approximately 1 in. in diameter; a quantity of sanguineopurulent material was also present within the uterus. In view of the fact that the ewes had been under constant observation since inoculation, these findings were taken as presumptive evidence of resorption.

There is no published information concerning total prenatal mortality-rates in flocks in which toxo. plasmosis is known to occur naturally; however, results from a Dorset Horn flock in south-eastern Queensland in which perinatal mortality due to toxoplasmosis has been diagnosed, indicate a large discrepancy between the number of ewes apparently conceiving and those eventually lambing. This discrepancy is only partly accounted for by abortions. It is suggested, therefore, that in some circumstances, foetal resorption may be more important than perinatal mortality as a manifestation of ovine toxoplasmosis.

Faculty of Veterinary Science,

I. D. SMITH

University of Queensland, Brisbane.

${ }^{1}$ Hartley, W. J., and Marshall, B. C., N.Z. Vet. J., 5, 118 (1957). ${ }^{2}$ Hartley, W. J.; Jebson, J. L., and McFarlane, D., Aust. Vet. J.,

${ }^{3}$ Johnson, K. G. and Studdert, M. J., A ust. Vet. J., 35, 502 (1959)

' Osborne, H. G., A ust. Vet. J., 35, 424 (1959).

${ }^{5}$ Beverley, J. K. A., and Watson, W. A., Nature, 184, 2041 (1959).

Cole, C. R., Sanger, V. L., Farrell, R. L., and Kornder, J. D., North Amer. Vet., 85, 265 (1954).
(19)

\section{BIOLOGY}

\section{Genetic Control of Oxytetracycline Biosynthesis}

More than ten years ago Bonner ${ }^{1}$ made an unsuccessful attempt to use inactive variants and biochemical mutants of Penicillium chrysogenum for studying the mechanism of penicillin biosynthesis. Since that time the mechanism of the biosynthesis of the antibiotic has apparently not been investigated in this way.

In 1956 we published a paper ${ }^{2}$ on the biosynthesis of oxytetracycline by methionine- and niacinerequiring mutants of Act. rimosus.

It was shown that both mutants require for the antibiotic production much greater amounts of these substances than is needed for their growth. Repeatedly isolated mutants with methionine and niacin deficiencies had the same properties. These results convinced us of the necessity of investigating the genetical control of the mechanism of the antibiotic biosynthesis, particularly the biosynthesis of oxytetracycline. In this connexion an attempt was made 